\title{
Appropriate medication prescribing in elderly patients: how knowledgeable are primary care physicians? A survey study in Parma, Italy.
}

\author{
Vittorio Maio, PharmD, MS, MPH \\ Jefferson School of Population Health \\ Eric Jutkowitz, BA \\ Jefferson School of Population Health \\ Karina Herrera BA, MS \\ Jefferson Medical College \\ Safiya Abouzaid PharmD

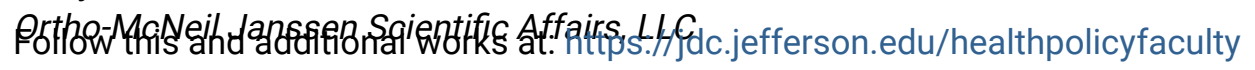

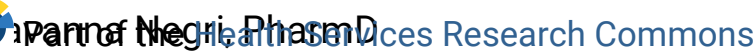

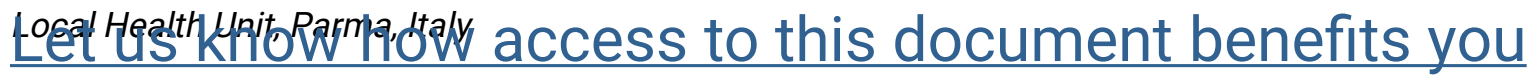

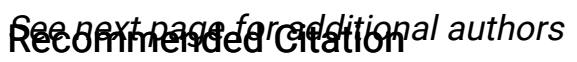

Maio, PharmD, MS, MPH, Vittorio; Jutkowitz, BA, Eric; Herrera BA, MS, Karina; Abouzaid PharmD, Safiya; Negri, PharmD, Giavanna; and Del Canale, MD, PhD, Stefano, "Appropriate medication prescribing in elderly patients: how knowledgeable are primary care physicians? A survey study in Parma, Italy." (2011). College of Population Health Faculty Papers. Paper 46.

https://jdc.jefferson.edu/healthpolicyfaculty/46

This Article is brought to you for free and open access by the Jefferson Digital Commons. The Jefferson Digital Commons is a service of Thomas Jefferson University's Center for Teaching and Learning (CTL). The Commons is a showcase for Jefferson books and journals, peer-reviewed scholarly publications, unique historical collections from the University archives, and teaching tools. The Jefferson Digital Commons allows researchers and interested readers anywhere in the world to learn about and keep up to date with Jefferson scholarship. This article has been accepted for inclusion in College of Population Health Faculty Papers by an authorized administrator of the Jefferson Digital Commons. For more information, please contact: JeffersonDigitalCommons@jefferson.edu. 


\section{Authors}

Vittorio Maio, PharmD, MS, MPH; Eric Jutkowitz, BA; Karina Herrera BA, MS; Safiya Abouzaid PharmD; Giavanna Negri, PharmD; and Stefano Del Canale, MD, PhD 


\title{
As submitted to:
}

\section{Journal of Clinical Pharmacy and Therapeutics}

\author{
And later published as:
}

\section{Appropriate medication prescribing in elderly patients: How Knowledgeable are primary care physicians? A survey study in Parma, Italy.}

\author{
Volume 36, Issue 4, August 2011, Pages 468-480 \\ DOI: $10.1111 / j .1365-2710.2010 .01195 . x$
}

Short title: Physicians' knowledge of appropriate prescribing in elderly patients

Vittorio Maio, PharmD, MS, MSPH, ${ }^{1}$ Eric Jutkowitz BA, ${ }^{1}$ Karina Herrera BA, MS, ${ }^{2}$ Safiya Abouzaid PharmD, ${ }^{3}$ Giovanna Negri, PharmD,${ }^{4}$ Stefano Del Canale, MD, $\mathrm{PhD}^{4}$

1. Jefferson School of Population Health, Thomas Jefferson University, Philadelphia, PA, USA

2. Center for Research in Medical Education and Health Care, Jefferson Medical College, Philadelphia, PA, USA

3. Ortho-McNeil Janssen Scientific Affairs, LLC

4. Local Health Unit, Parma, Italy

\section{Corresponding author:}

Vittorio Maio, PharmD, MS, MPH

Associate Professor

Jefferson School of Population Health

1015 Walnut Street, Suite 115

Philadelphia, PA 19107

Tel.215-955-1821

Fax 215-923-7583

Email vittorio.maio@jefferson.edu 


\section{Word count: 3197}

Dr. Maio is an Associate Professor, Mr. Jutkowitz is a Post-Baccalaureate Fellow in Health Economics and Outcomes Research, and Dr. Abouzaid is an Outcomes Research Fellow in the Jefferson School of Population Health, Thomas Jefferson University, Philadelphia, PA, USA. Mrs. Herrera is a Research Assistant in the Center for Research in Medical Education and Health Care, Jefferson Medical College, Philadelphia, PA, USA. Dr. Negri is Responsible for the Pharmaceutical Services and Dr. Del Canale is a General Practitioner, both work in the Local Health Unit of Parma, Italy. 


\section{Acknowledgements}

This research was supported through a collaborative agreement between the Parma Local Health Unit, Parma, Italy, and the Jefferson School of Population Health, Thomas Jefferson University, Philadelphia, PA, USA. Dr. Maio had full access to all the data in the study and takes responsibility for the integrity of the data and the accuracy of the data analysis. Dr. Abouzaid's fellowship is sponsored by Ortho-McNeil Janssen Scientific Affairs, LLC, Titusville, NJ. The authors have no conflicts of interest relevant to this research.

We thank Maria Lazzarato, MD, and Massimo Fabi, MD, from the Local Health Unit, Parma, Italy, Andrea Donatini, MSc, from the Healthcare Authority, Regione Emilia-Romagna, Italy, and Daniel Z. Louis, MS, from the Center for Research in Medical Education and Health Care at Jefferson Medical College, Philadelphia, PA, for their support and assistance.

We acknowledge Christine W. Hartmann, PhD, Christine Arenson, MD, Barbara Roehl, MD, MBA, James J. Diamond, PhD, Amy R. Talati, PharmD, for the development of the original survey instrument and thank them for allowing us to use the survey for this study. We also thank Alberto Bifani, MD, Gianluca Boldrocchi, MD, Sigismondo Ferrante, MD, Giuseppina Paulillo, MD, Pietro Pellegrini, MD, Paolo Tosini, MD, and Livio Verti, MD, for their assistance in reviewing and refining the Italian version of the survey instrument. 


\section{Summary}

What is known and Objective

Increasing attention is being paid to inappropriate medication prescribing for the elderly. A growing body of studies have detected a prevalence of inappropriate prescribing ranging from 12\%-40\% worldwide, including Regione Emilia-Romagna, Italy. In order to improve quality of prescribing, a multi-phase pilot project in the Local Health Unit (LHU) of Parma, Regione Emilia-Romagna, was established. This phase aimed to assess primary care physicians' knowledge of appropriate prescribing in elderly patients.

\section{Methods}

155 primary care physicians (51\% of the total), convened by the LHU of Parma for an educational session, were asked to complete anonymously a 19-item paper survey. Knowledge of inappropriate medication use in the elderly was assessed using 7 clinical vignettes based on the 2002 Beers Criteria. Topics tested included hypertension, osteoarthritis, arrhythmias, insomnia, and depression. Data regarding physician's perceived barriers to appropriate prescribing for elderly patients was also collected. To evaluate the relationship between physician knowledge scores and physician characteristics, physicians were classified as having a "low score" (3 or below) or a "high score" (6 or more) with respect to their knowledge of prescribing for the elderly.

\section{Results and Discussion}

All physicians completed the survey. Most physicians (88\%) felt confident in their ability to prescribe appropriate medications for the elderly. Thirty-nine physicians (25\%) 
received a "high score" compared to $26(17 \%)$ who received a "low score." "Lower score" respondents had been in practice for a longer time $(\mathrm{p}<0.05)$ than "higher score" respondents. Perceived barriers to appropriate prescribing included potential drug interactions ( $79 \%$ of respondents) and the large number of medications a patient is already taking $(75 \%)$.

\section{What is new and Conclusion}

The study results show an unsatisfactory knowledge of appropriate prescribing among primary care physicians in the LHU of Parma, especially among older physicians.

Educational strategies tailored to primary care physicians should be establish to enhance knowledge in this area and improve quality of prescribing

Keywords: appropriate prescribing, elderly, knowledge of medication, Beers criteria, clinical vignettes, primary care physicians 


\section{What is known and Objective}

Elderly patients are the most frequent users of medications. On average the elderly consume three times as many medications as the non-elderly (1) and use 2 to 6 prescribed medications simultaneously (2). In addition to high rates of medication consumption, age-related physiological changes and co-morbidities that often modify medication metabolism patterns and pharmacological activity can place the elderly at significant risk for medication-related issues (3). One such issue is the exposure to potentially inappropriate prescribing (PIP), possibly leading to increased outpatient visits (4), hospitalization rates, and the likelihood of death (5).

Although prescribing medications for the elderly is a routine activity in clinical practice, physicians can face a difficult task in selecting the right medication or combination of medications for elderly patients. No professional organization has yet developed guidelines for effective and safe therapeutic use of medications in the elderly. However, a number of methods have been proposed to evaluate the quality of prescribing in the elderly, the most widely cited of which is the Beers criteria $(2,6,7,8,9,10)$. Based on a consensus panel, the Beers criteria was originally proposed in 1991 and later revised in 2002. The Beers criteria explicitly define a list of medications or medication classes that should generally be avoided in the elderly or when a specific underlying disease or condition exists (11).

Using the Beers criteria, a growing body of studies have detected a prevalence of potentially inappropriate prescribing (PIP) ranging from $12 \%-40 \%$ worldwide in several 
settings, including inpatient, outpatient, and nursing homes (12-14). In Italy, a population-based cohort study conducted in the Regione Emilia-Romagna--a large northern region with approximately 4.2 million inhabitants--applied the 2002 Beers criteria, and found that in 2001, $18 \%$ of elderly outpatients were exposed to PIP (14). Despite the high rates of PIP reported in the literature, there have been only a few published studies evaluating physician knowledge of prescribing to the elderly. Evidence from these studies suggests that family physicians often feel inadequate and uninformed when prescribing to elderly patients $(15,16,17)$.

In order to promote and improve the quality of prescribing for elderly patients in primary care, a multi-phase pilot project in the Local Health Unit (LHU) of Parma, Regione Emilia-Romagna, was established (18). The objective of the pilot project described in this paper was to assess primary care physicians' knowledge of appropriate prescribing in elderly patients.

\section{Methods}

This study employed a cross-sectional survey design. Thomas Jefferson University's institutional review board reviewed and approved the study protocol.

\section{Participants}


The study population included all primary care physicians (303) from the Local Health Unit (LHU) of Parma, Regione Emilia-Romagna, Italy. ${ }^{1}$ The 303 physicians deliver outpatient healthcare services to a population of approximately 400,000 inhabitants.

\section{Survey Questionnaire}

Due to the absence of a validated tool to measure physicians' knowledge of prescribing for the elderly, the questionnaire used for this study was adapted from a questionnaire that was previously developed for a similar study conducted in the United States, which has been described elsewhere (19). In essence, the survey questionnaire consisted of 25 items on a variety of topics. Knowledge of prescribing was assessed via clinical vignettes using the 2002 Beers criteria as a reference; the vignettes were reviewed for value and clarity by an advisory panel of twenty individuals, physicians and researchers with expertise in family medicine, geriatrics, statistics, and outcomes research.

For this study, the original English questionnaire was translated into Italian and back translated into English for accuracy and validity. Some items in the English version of the survey were eliminated in the Italian version because they were not relevant to the delivery of healthcare services in Italy. Other items were modified to capture the organizational and cultural characteristics of the Italian outpatient settings. Some vignettes were also adapted to reflect the therapeutic choices available in the Italian drug

\footnotetext{
${ }^{1}$ In Italy, primary care is provided to adults and children, by primary care physicians and pediatricians, who are paid on a capitation basis under a contractual agreement with the Italian National Health Service (SSN). After graduation from a medical school, physicians who wish to become a primary care physician register on a national list. Ranking on the list is based on academic qualifications and, as of 1995, on successful participation in a two-year primary care training course (20).
} 
market. The final Italian questionnaire included 19 items, of which 7 were clinical vignettes, which covered a variety of topics (in appendix).

Key demographic characteristics of physicians were collected including age, sex, type of training, and number of years in practice. Physician exposure to elderly patients was captured as the percent of patients seen by the physician in the ambulatory setting who were elderly and the amount of time the physician spent working in long-term care facilities.

Physicians were asked to assess their confidence in prescribing for the elderly by rating their agreement or disagreement with the following statement: "I have confidence in my ability to prescribe appropriate medication for the elderly," using a 5-point Likert scale, where (1) meant strongly agree and (5) meant strongly disagree and (3) represented indifference to the statement. To further assess knowledge of prescribing for the elderly, physicians were asked to evaluate how frequently they used academic resources using a 4-point scale (frequently, sometimes, rarely, and never used), when prescribing to this patient population. In addition, physicians were asked to self-rate their knowledge and use of the Beers criteria using a 5-point scale (often used, sometimes used, rarely used, known but never used, and never heard of).

The 7 clinical vignettes were meant to capture knowledge of medications to be avoided in the elderly. Overall, the vignettes focused on the therapeutic approaches for diseases frequently observed in the elderly. Three vignettes (\#1,2, and 7) focused on the 
therapeutic issues in patients with hypertension and arrhythmia, three (\#3, 4, and 5) dealt with the therapeutic options for patients with depression, anxiety, and insomnia, and one (\#6) addressed the therapeutic choices for pain management in patients with arthritis.

Respondents were expected to choose one out of four multiple choices given.

Finally, physicians were asked to rate their level of agreement on 13 potential barriers to appropriate prescribing using a 5-point Likert scale, where (1) meant strongly agree and (5) meant strongly disagree and (3) represented indifference to the statement.

\section{Data collection and analysis}

In November 2007 the General Director of the LHU of Parma invited all primary care physicians practicing in the LHU for an educational session on appropriateness of prescribing for the elderly. Of the 303 physicians, 155 (51\%) attended the session. Before the beginning of the educational presentation, physicians were asked to complete a paper version of the survey. Participation was voluntary and anonymous.

Responses were entered in an Excel spreadsheet (Microsoft Office 2007) for the analysis. Descriptive statistics were computed for all variables of interest. For purposes of analysis, physicians' demographic responses were aggregated into separate categories as follows:

- Training (4 categories): Geriatric Medicine, Internal Medicine, Other, and None/Not specified

- Years of practice (4 categories): 10 years or less, 11 to 20 years, 21 to 25 years, and 26 years or greater 
In addition, the 5-point values of the scale used to determine the confidence in prescribing were converted into a dummy variable. Response values of (1) strongly agree and (2) agree were grouped into a "more confident" category; while response values of (3) indifference, (4) disagree, and (5) strongly disagree were grouped into a "less confident" category. Responses regarding commonly used sources of information were dichotomized into "frequently used" (frequently and sometime) and "rarely used" (rarely and never). Responses for the perceived barriers to prescribing, were also dichotomized into "important barrier" (strongly agree and agree) and "not important barrier" (indifference, disagree, and strongly disagree).

To measure physicians' knowledge of prescribing for the elderly, we computed the correct responses of survey participants for the 7 clinical vignettes. Physicians received 1 point for each vignette that was answered correctly, and 0 points if they answered incorrectly (total possible score 0-7). To evaluate the relationship between physician knowledge scores and physician characteristics, we reviewed the distribution of scores (Fig. 1). Because a large proportion of respondents (58\%) reported a score of 4 or 5, we focused our analysis on those physicians who reported significantly better or worse on knowledge score. Therefore, physicians were classified as having a "low score" (3 or below) or a "high score" (6 or more) with respect to their knowledge of prescribing for the elderly. A bivariate comparison between "low score" and "high score" was then performed. Two-side Chi-Square analyses were employed for categorical variables. For these analyses, based on the distribution of results we converted the variable years of 
practice into three categories (10 years or less, 11 to 25 years, and 26 years or greater) and the variable elderly patient population into three categories (24\% or less, $25 \%$ to $49 \%$, and $50 \%$ or greater).

In addition, we converted both the knowledge and use of Beers criteria into a dichotomous variable- "some use" versus "no use", and the amount of time spent in long term facilities-“any" versus "never." Finally, we included years of practice and excluded age because the two variables were shown to be highly correlated in a separate analysis $(\mathrm{r}=0.96)$. For all analyses, a value of $\mathrm{p}<0.05$ was considered statistically significant. All analyses were performed using SAS version 9.1 (SAS Institute Inc., Cary, North Carolina, USA).

\section{Results and Discussion}

All 155 physicians who attended the educational session held by the LHU of Parma completed the survey. Respondents were predominantly male (76\%) and the mean age was $54.2 \pm 5.0$ (Table 1). Thirty-eight percent of respondents had $\geq 26$ years of practice. Regarding education, $6 \%$ of the respondents received training in Geriatric Medicine and 9\% received training in Internal Medicine. Half of the physicians had their main practice in an urban area. Regarding exposure to elderly patients, about $60 \%$ of physicians reported that $25 \%$ or more of their patient population was 65 years or older and approximately two thirds of respondents were currently providing some care in a longterm care facility (Table 2). 
Eighty-eight percent of physicians were confident in prescribing appropriate drugs to the elderly (Table 2). Respondents reported that the source of information usually consulted when prescribing for the elderly were medical textbooks (75\%), medical journals (59\%), medical colleagues (58\%), and software on handheld device (45\%). Regarding knowledge and usage of the Beers criteria, $69 \%$ of respondents never heard of the criteria, approximately $16 \%$ knew and had some use of the criteria, while $15 \%$ knew of but never used the criteria.

Overall, a total of 90 respondents (58\%) reported a score of 4 or 5 on the vignettes (Figure 1). Thirty-nine physicians (25\%) were found to be in the "high score" category while 26 physicians (17\%) were in the "low score" category. More than three-fourths of physicians answered the three questions on medication prescribing for mental issues correctly (Table 3). For questions regarding cardiovascular disease, only half of the respondents rightly chose to first eliminate doxazosin in a multi-drug regimen to treat a well-controlled hypertensive patient, and only $19 \%$ of respondents correctly chose to avoid the use of amiodarone in an elderly patient with arrhythmia. In the area of musculoskeletal disease, approximately half of the respondents (57\%) correctly chose not to use NSAIDs as chronic therapy for pain symptoms in an elderly patient with arthritis.

Chi-square analyses revealed no significant difference in sex, training, exposure to elderly patients, location of practice, confidence in prescribing, and the use of the Beers criteria between physicians with "high score" and "low score" (Table 4). A significant difference was only found in the number of years in practice. Notably, 27\% and 55\% of 
physicians with a "low score" were in practice for $11-25$ and $\geq 26$ years, while $64 \%$ and $22 \%$ of physicians with "high score" were in practice for $11-25$ and $\geq 26$ years $(\mathrm{p}<0.05)$.

When asked about the barriers impeding appropriateness of prescribing in the elderly, the top five factors cited by respondents were drug-drug interactions (79\%), polypharmacy (75\%), patient not reporting intolerance to a specific medication (48\%), communicationrelated issues with other physicians participating in a patient's care (46\%), and cost to patient $(42 \%)$.

\section{Discussion}

Vignette scores of the primary care physicians who completed the questionnaire suggest that there is a gap between physicians' high self-rated confidence in prescribing for the elderly and their knowledge of the appropriate use of medication for this patient population. Although the tool used to assess the knowledge of appropriate prescribing has intrinsic limitations, the distribution of vignette scores among the physicians indicates that there is significant variance in how physicians appropriately prescribe for elderly patients. If we assume that scores on the vignettes are in fact indicative of knowledge, then only $25 \%$ of respondents had adequate knowledge of prescribing and, on the contrary, $17 \%$ of physicians had very poor knowledge of prescribing.

Our results reinforce earlier findings that physician knowledge of prescribing for the elderly is inadequate (15). Due to the potential harm of inappropriate prescribing in the elderly, it is imperative that primary care physicians be aware of the most appropriate 
therapeutic choices. Potential strategies for improving physician knowledge of prescribing in the elderly could include development of continuing medical education on geriatric pharmacology and incentives to promote the use of recommendations for appropriate prescribing.

Our study suggests that physicians who have been in practice a greater number of years are more likely score lower on the clinical vignettes. Similarly, several studies in the literature have found that physicians who have been in practice longer are at risk of providing lower quality care (21) possibly due to practice inertia and the physicians inability to adapt to new guidelines (22). In order to improve quality of prescribing by older physicians, continuing education courses could target primary care physicians according to their age and years in practice. However, while this is a simple solution in theory, we recognize it may be difficult to implement and organize in practice.

Three of the vignettes were frequently answered incorrectly. The first asked physicians to choose an appropriate chronic therapy for a 75 year-old patient with arthritis. A large minority (43\%) of physicians chose NSAIDs for long-term therapy despite the explicit warning in the updated Beers criteria against such therapy in the elderly. Prolonged ( $>15$ days) NSAID use in this patient population is associated with a high risk of severe adverse drug events (23) and progressive or abrupt worsening of renal function (24). In addition, elderly patients with comorbid diseases such as diabetes, heart failure, cirrhosis or simple volume-depletion who are exposed to prolonged therapies with NSAIDs are more likely to retain sodium leading to edema, heart failure exacerbation or blunted 
response to hypertensive medications (25). Moreover both non-selective NSAIDs and COX-2 selective inhibitors are recognized agents able to induce dangerous hyperkalemia in frail elderly patients with heart failure (26).

The second vignette on which physicians also scored poorly was designed to assess knowledge of multidrug antihypertensive therapy. In this vignette, half the physicians did not eliminate doxazosin as first-line treatment for hypertension. Current Hypertension Treatment guidelines suggest that doxazosin be used only as a second or third line therapy for most hypertensive patients because high probabilities of cardiovascular events (namely heart failure) are related to its use (27). Our finding of a low rate of adherence to antihypertensive therapy guidelines is also consistent with a recent observational study conducted in Italy (28).

Finally, less than a quarter of physicians surveyed correctly selected amiodarone as an antiarrhythmic agent that should be avoided in an 85 year-old patient with relapsing atrial fibrillation. Despite its widespread use, amiodarone is approved by FDA only for the treatment of lethal arrhythmias. In Italy, amiodarone has many indications including the prevention of relapsing atrial fibrillation and maintenance of sinus rhythm, but its potential toxicity in the elderly (e.g., ocular, thyroid, pulmonary, coetaneous, hepatic, proarrythmic toxicity) calls for more careful use as outlined in the Beers Criteria. Amiodarone should in fact be reserved only for elderly patients with relapsing atrial fibrillation associated with structural heart disease at a very low dosage $(<100 \mathrm{mg} / \mathrm{day})$ (29). 
Although the Beers criteria are widely cited in the literature, almost three-fourths of the physicians reported to be unaware of them. Because the majority of the published literature is written in English, one potential explanation for physicians' lack of knowledge of the Beers criteria is the language barrier. Several studies have demonstrated that Italian physicians have a limited knowledge of English, and as such tend to use English evidence and clinical guidelines less than English speaking physicians $(30,31)$. This suggests that educational interventions for primary care physicians in Italy should aim to improve physicians' knowledge of English as a means to promote the use of evidence-based medicine.

Results also indicate that physicians preferred textbooks and medical journals to software handheld devices as a resource when prescribing to their older patients. However, there is evidence that electronic devices may enable physicians to more easily stay current with the literature (32). Handheld devices have the capability to support decision-making tools, which can promptly help physicians choose the most appropriate medication for a specific patient. Policy makers of the LHU of Parma should encourage and place incentives for primary care physicians to adopt handheld devices for consultation while prescribing for their elderly patients.

Finally, physicians cited drug-drug interactions and polypharmacy as primary barriers impeding appropriate prescribing. Intuitively, this is because elderly patients are frequently exposed to a multi-drug regimen and as such physicians often need to avoid certain appropriate medications because of the potential for drug-drug interactions. Interestingly, about half of the physicians perceived the lack of communication with 
other physicians involved in the patients care as an important barrier to appropriate prescribing. Lack of communication between physicians could have substantial implications for patient safety, satisfaction and clinical outcomes (33). Due to the presence of several comorbidities, the elderly generally visit multiple physicians, making communication among professionals crucial to improving coordination of care.

Our study is not without limitations. All data were self-reported and therefore subject to bias. Because this study adopted a cross-sectional methodology, determining causality among variables should be done with caution. In addition, only half of the physicians in the LHU of Parma completed the survey and so our results are susceptible to nonresponse bias (34). Physicians who completed the survey could also be biased as they may either work more frequently with the elderly or have a greater interest in issues of prescribing to the elderly. However, when we compared the demographic characteristics of survey participants with those of all primary care physicians in the LHU of Parma, we found no statistically significant differences between the groups. This provides some reassurance on the validity of the study findings. It should be noted that because the study was conducted with primary care physicians in one LHU, results cannot be generalized to the overall population of primary care physicians in Italy. To assess physician knowledge of prescribing for the elderly we used clinical vignettes. Formal tools, such as tests and examinations, may be more suitable; however, vignettes have been used in research for over 30 years and are a validated tool for deriving information $(35,36)$. 
What is new and Conclusion: The study results show an unsatisfactory knowledge of appropriate prescribing among primary care physicians in the LHU of Parma, especially among older physicians. As the Italian population continues to age and the number of new drugs entering the market increases, primary care physicians must become more knowledgeable about appropriate prescribing in this vulnerable population. Policy makers should develop strategies to improve the quality of physicians' prescribing for elderly patients. 


\section{References}

1. Gallagher P, Barry P, O'Mahony D (2007) Inappropriate prescribing in the elderly. Journal of Clinical Pharmacy and Therapeutic, 32, 113-21.

2. Chin MH, Wang LC, Jin L, Mulliken R, Walter J, Hayley DC et al. (1999) Appropriateness of medication selection for older persons in an urban academic emergency department. Academic Emergency Medicine, 6, 1232-41.

3. Mallet L, Spinewine A, Huang A (2007) The challenge of managing drug interactions in elderly people. The Lancet, 370, 185-91.

4. Fillenbaum GG, Hanlon JT, Landerman LR, Artz MB, O'Connor H, Dowd B et al. (2004) Impact of inappropriate drug use on health services utilization among representative older community-dwelling residents. The American Journal of Geriatric Pharmacotherapy, 6, 92-101. 5. Lau DT, Kasper JD, Potter DEB, Lyles A, Bennett RG (2005) Hospitalization and death associated with potentially inappropriate medication prescriptions among elderly nursing home residents. Achieves of Internal Medicine, 165, 68-74.

6. Gurwitz JH, Rochon P (2002) Improving the quality of medication use in elderly patients: A not-so-simple prescription. Achieves of Internal Medicine, 162, 1670-2.

7. Meredith S, Feldman PH, Frey D, Hall K, Arnold K, Brown NJ et al. (2001) Possible medication errors in home healthcare patients. The Journal of the American Geriatrics Society, 49, 719-24.

8. Gallagher P, Ryan C, Byrne S, Kennedy J, O'Mahony (2008) STOPP (Screening Tool of Older Person's Prescriptions) and START (Screening Tool to Alert doctors to Right Treatment). Consensus validation. Internatioal Journal of Clinical International Journal of Clinical Pharmacology, Therapy, \& Toxicology, 46, 72-83. 
9. Laroche ML, Charmes JP, Merle L (2007) Potentially inappropriate medications in the elderly: a French consensus panel list. Eur J Clin Pharmacol, 63, 725-731.

10. McLeod PJ, Huang AR, Tamblyn RM, Gayton DC (1997) Defining inappropriate practices in prescribing for elderly people: a national consensus panel. Can Med Assoc J, 156, 385-391. 11. Beers MH, Ouslander JG, Rollingher I, Reuben DB, Brooks J, Beck JC (1991) Explicit criteria for determining inappropriate medication use in nursing home residents. Achieves of Internal Medicine, 151, 1825-32.

12. Fialova D, Topinkova E, Gambassi G, Finne-Soveri H, Jonsson PV, Carpenter I et al. (2005) Potentially inappropriate medication use among elderly home care patients in Europe. Journal of the American Medical Association, 293, 1348-58.

13. Zhan C, Sangl J, Bierman AS, Miller MR, Friedman B, Wickizer SW et al. (2001) Potentially inappropriate medication use in the community-dwelling elderly: Findings from the 1996 medical expenditure panel survey. Journal of the American Medical Association, 286, 2823-9.

14. Maio V, Yuen E, Novielli K, Smith K, Louis D (2006) Potentially inappropriate medication prescribing for elderly outpatients in Emilia Romagna, Italy. Drugs \& Aging, 23, 915-924.

15. Ferry ME, Lamy PP, Becker LA (1985) Physicians' knowledge of prescribing for the elderly A study of primary care physicians in Pennsylvania. The Journal of the American Geriatrics Society, 33, 616-25.

16. Fantino B, Voirin N, Laforest L, et al (2006) Primary care physicians' behaviors towards risk of iatrogenesis in elderly patients. European Journal of Clinical Pharmacology, 62, 563-570 17. Gurwitz JH, Field TS, Harrold LR, Rothschild J, Debellis K, Seger AC, Cadoret C, Fish LS, Garber L, Kelleher M, Bates DW (2003) Incidence and preventability of adverse drug events among older persons in the ambulatory setting. JAMA 289:1107-1116 
18. Maio V, Del Canale S, Abouzaid S (In Press) Using explicit criteria to evaluate the quality of prescribing in elderly Italian outpatients: A cohort study. Journal of Clinical Pharmacy and Therapeutics.

19. Ramaswamy R, Maio V, Diamond J, Talati R, Roehl B (2009) Physician knowledge and potentially inappropriate prescribing for the elderly: A multi-institutional cross-sectional survey. Annual Scientific Meeting of the American Geriatrics Society.

20. European Observatory on Health Systems and Policies. Health Systems in Transition. Italy. (2009) Health system review. 11

21. Choudhry NK, Fletcher RH, Soumerai SB (2005) Systematic review: The relationship between clinical experience and quality of health care. Annals of Internal Medicine, 142, 260-73. 22. Majumdar SR, Soumerai SB (2003) Why most interventions to improve physician prescribing do not seem to work. Canadian Medical Association Journal, 169, 30-1.

23. Fick DM, Cooper JW, Wade WE, Waller JL, Maclean JR, Beers MH (2003) Updating the beers criteria for potentially inappropriate medication use in older adults: Results of a US consensus panel of experts. Achieves of Internal Medicine, 163, 2716-24.

24. Gooch K (2007) NSAID use and progression of chronic kidney disease. American Journal of Medicine, 120, 280-e1-7.

25. Rabb H, Colvin RB (2007) Case 31-2007 -- A 41-year-old man with abdominal pain and elevated serum creatinine. New England Journal of Medicine, 357, 1531-41.

26. Perazella MA (2002) COX-2 selective inhibitors: Analysis of the renal effects. Expert Opinion on Drug Safety, 1, 53-64.

27. Chobanian AV, Bakris GL, Black HR, Cushman WC, Green LA, Izzo JL, Jr et al. (2003) The seventh report of the joint national committee on prevention, detection, evaluation, and treatment of high blood pressure: The JNC 7 report. Journal of the American Medical Association, 289, 
28. Maio V, Gagne JJ (2010) Impact of ALLHAT publication on antihypertensive prescribing patterns in Regione Emilia-Romagna, Italy. Journal of Clinical Pharmacy and Therapeutics, 35, $55-61$.

29. Zimetbaum P (2007) Amiodarone for atrial fibrillation. New England Journal of Medicine, 356, 935-41.

30. De Vito C, Carmelo Nobile G, Furnari G, Pavia M, De Giusti M, Angelillo I et al. (2009) The role of education in improving physicians' professional use of economic evaluations of health interventions: Some evidence from a cross-sectional survey in Italy. Evaluation \& the Health Professions, 32, 249-63.

31. De Vito C, Nobile CG, Furnari G, Pavia M, De Giusti M, Angelillo IF et al. (2009) Physicians' knowledge, attitudes and professional use of RCTs and meta-analyses: A crosssectional survey. European Journal of Public Health, 19, 297-302.

32. Fontelo P, Ackerman M, Kim G, Locatis C (2003) The PDA as a portal to knowledge sources in a wireless setting. Telemedicine and e-Health, 9, 141-7.

33. Kripalani S, LeFevre F, Phillips CO, Williams MV, Basaviah P, Baker DW (2007) Deficits in communication and information transfer between hospital-based and primary care physicians: Implications for patient safety and continuity of care. Journal of American Medical Association, 297, 831-41.

34. Bergk V, Gasse C, Schnell R, Haefeli W (2005) Mail surveys: Obsolescent model or valuable instrument in general practice research? Swiss Medical Weekly, 35, 189-91.

35. Peabody JW, Luck J, Glassman P, Jain S, Hansen J, Spell M et al. (2004) Measuring the quality of physician practice by using clinical vignettes: A prospective validation study. Annals of Internal Medicine,

141, 771-80.

36. Veloski J, Tai S, Evans AS, Nash DB (2005) Clinical vignette-based surveys: A tool for assessing physician practice variation. American Journal of Medical Quality. 20, 151-7. 
$-24-$ 


\section{Appendix}

Thank you for taking the time to respond to this survey regarding physician attitudes and knowledge about medication prescribing for the elderly. Below you will find a short questionnaire regarding the physician's attitude for prescribing in the elderly. When responding to the questionnaire, the word "elderly" refers to subjects that are 65 years or older. Your participation is voluntary and your responses will remain anonymous. Completing the questionnaire should take no more than ten minutes. Thanks again for your participation!

1. Please indicate the extent to which you agree or disagree with the following statement.

\begin{tabular}{|l|c|l|l|l|l|}
\hline & $\begin{array}{c}\text { Strongly } \\
\text { Agree }\end{array}$ & Agree & Neutral & Disagree & $\begin{array}{c}\text { Strongly } \\
\text { Disagree }\end{array}$ \\
\hline $\begin{array}{l}\text { I have confidence in my ability to } \\
\text { prescribe appropriate medications for } \\
\text { the elderly. }\end{array}$ & & & & & \\
\hline
\end{tabular}

2. During an encounter with an elderly patient, please indicate how often you rely on each form of reference when making medication prescribing decisions.

\begin{tabular}{|l|l|l|l|l|}
\hline & Often used & $\begin{array}{c}\text { Sometimes } \\
\text { used }\end{array}$ & Rarely used & Never used \\
\hline Medical Text & & & & \\
\hline Medical Journals & & & & \\
\hline $\begin{array}{l}\text { Computer (e.g. websites, } \\
\text { prompts, google) }\end{array}$ & & & & \\
\hline $\begin{array}{l}\text { Handheld device (e.g. epocrates, } \\
5 \text { minute MD) }\end{array}$ & & & & \\
\hline $\begin{array}{l}\text { Consultant (e.g. pharmacist, } \\
\text { other physicians) }\end{array}$ & & & & \\
\hline
\end{tabular}

3. Please indicate how often you use the following resource to guide medication prescribing in your elderly patients.

\begin{tabular}{|l|l|c|c|c|c|}
\hline & Often use & $\begin{array}{c}\text { Sometimes } \\
\text { use }\end{array}$ & $\begin{array}{c}\text { Rarely } \\
\text { use }\end{array}$ & $\begin{array}{c}\text { Know of but } \\
\text { never use }\end{array}$ & $\begin{array}{c}\text { Never heard } \\
\text { of resource }\end{array}$ \\
\hline
\end{tabular}


For the following seven clinical scenarios, please note that some questions ask for the most APPROPRIATE medication while others ask for which medication to AVOID. Choose the single best answer for each case.

4. A 77 year old patient with a history of hypertension is simultaneously taking hydrochlorathiazide, metoprolol, lisinopril, and doxazosin. The blood pressure is well controlled and you would like to eliminate a medication. The patient has no other medical problems. Which medication would you first eliminate?

$\begin{array}{ll}\square & \text { Hydrochlorathiazide } \\ \square & \text { Metoprolol } \\ \square & \text { Lisinopril } \\ \square & \text { Doxazosin }\end{array}$

5. An 85 year old patient of yours has a history of recurrent atrial fibrillation. Which medication would you like to avoid because its prescription is rarely appropriate?

$\begin{array}{ll}\square & \text { Propafenone } \\ \square & \text { Amiodarone } \\ \square & \text { Sotalol } \\ \square & \text { Atenolol }\end{array}$

6. You would like to start pharmacological treatment for a 68 year old patient with depression. The patient has no other medical problems. Which medication would be your first choice to prescribe?

$\begin{array}{ll}\square & \text { Amitriptyline } \\ \square & \text { Fluoxetine } \\ \square & \text { Nortryptyline } \\ \square & \text { Sertraline }\end{array}$

7. An 82 year old patient is beginning physical therapy rehabilitation after a hospital stay. The patient is quite anxious and may not maximally benefit from therapy if you do not prescribe a medication to address anxiety. There is no history of unconsciousness or falls. You have decided to start a low dose of benzodiazepine. Which medication would be most appropriate in this situation?

$\begin{array}{ll}\square & \text { Alprazolam } \\ \square & \text { Clorazepate } \\ \square & \text { Chlordiazepoxide } \\ \square & \text { Diazepam }\end{array}$


8. A 70 year old patient is having trouble sleeping. The suggestions you have made on correct sleep hygiene has had no positive success. Thus, you decide to prescribe a short course of treatment. The patient has no other medical problems. Which medication would be your first choice to prescribe?
口 Diazepam
$\square \quad$ Clorazepate
$\square \quad$ Zolpidem
口 Flurazepam

9. A 75 year old patient has arthritis pain and you have decided to start long term therapy to help improve symptoms. Which medication would be your first choice to prescribe?

$\begin{array}{ll}\square & \text { Naproxen } \\ \square & \text { Piroxicam } \\ \square & \text { Paracetamol + Codeine } \\ \square & \text { Indometacine }\end{array}$

10. Despite taking numerous medicines, your 86 year old patient has poorly controlled hypertension. The patient has a progressive history of stroke and dementia. Therefore, you decide to modify the patient's therapeutic regimen. Which medication would you avoid due to potential CNS side effects?

$\begin{array}{ll}\square & \text { Atenolol } \\ \square & \text { Amlodipine } \\ \square & \text { Lisinopril } \\ \square & \text { Clonidine }\end{array}$

11. Please indicate the degree to which you agree that the following are BARRIERS to appropriate prescribing for your elderly patients.

\begin{tabular}{|l|l|l|l|l|l|}
\hline $\begin{array}{l}\text { Limited number of medications } \\
\text { reimbursed by the Italian } \\
\text { National Healthcare System }\end{array}$ & $\begin{array}{c}\text { Strongly } \\
\text { Agree }\end{array}$ & Agree & Neutral & Disagree & $\begin{array}{c}\text { Strongly } \\
\text { Disagree }\end{array}$ \\
\hline $\begin{array}{l}\text { Limited time available during a } \\
\text { patient visit }\end{array}$ & & & & & \\
\hline $\begin{array}{l}\text { Lack of acceptable therapeutic } \\
\text { alternatives }\end{array}$ & & & & & \\
\hline Potential drug-drug interactions & & & & & \\
\hline Cost of medication to patient & & & & & \\
\hline $\begin{array}{l}\text { Patient request to begin a specific } \\
\text { medication }\end{array}$ & & & & & \\
\hline $\begin{array}{l}\text { Patient request to maintain a } \\
\text { specific medication }\end{array}$ & & & & & \\
\hline $\begin{array}{l}\text { Lack of information about which } \\
\text { medications a patient is already } \\
\text { taking }\end{array}$ & & & & & \\
\hline
\end{tabular}




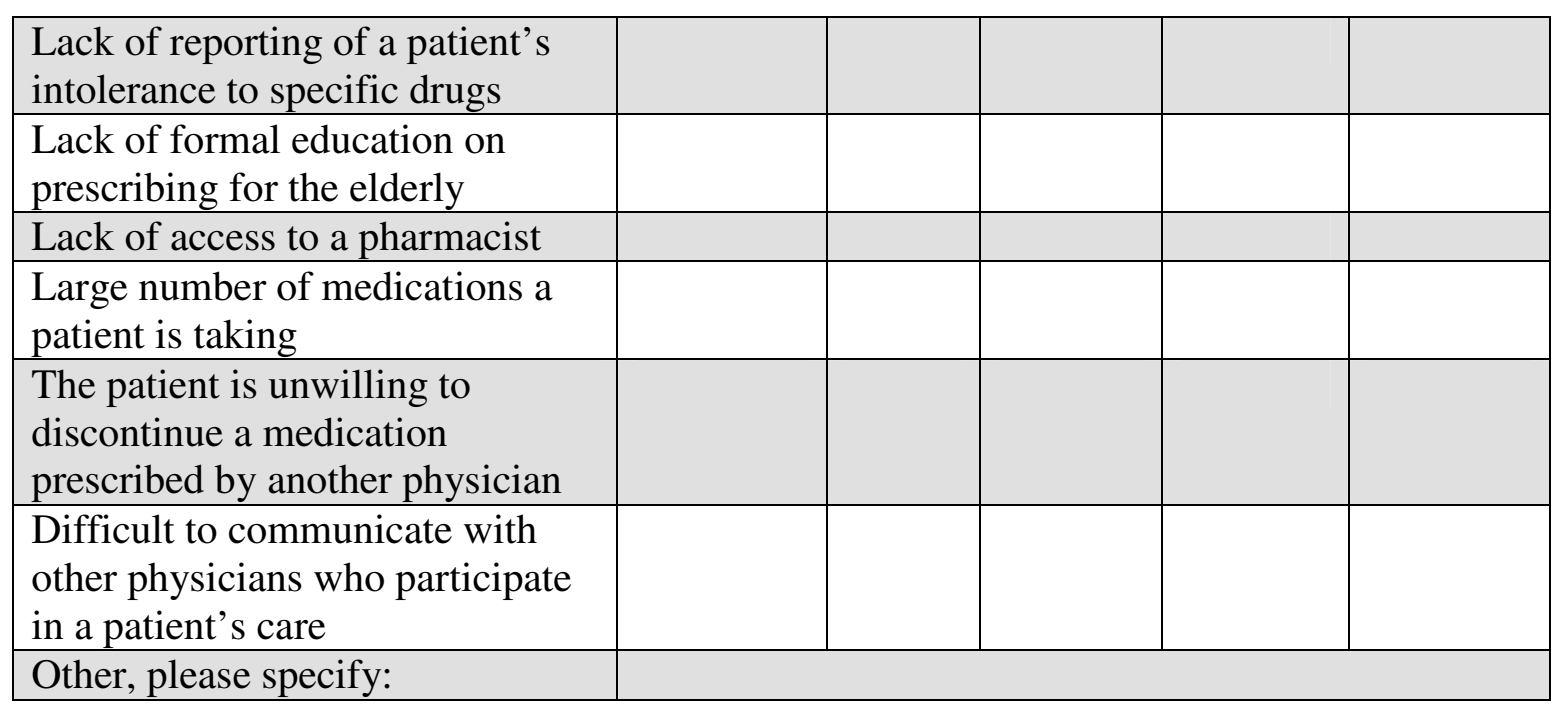

We would like to collect some information about your practice.

12. In what year did you graduate from medical school?

13. In what year did you begin to practice medicine under the Italian National Healthcare System?

14. Please specify which residency or fellowship you attended

15. Age:

16. Gender

$\square$ Male $\square$ Female

17. How would you describe the location of your practice?

$\square$ Urban $\square$ Suburban $\square$ Rural

18. What percent of your patient population do you estimate to be 65 and over?

口 Less than $10 \% \quad \square 10 \%-24 \% \quad \square 25 \%-49 \% \quad \square 50 \%$ or more

19. How frequently do you currently provide patient care in nursing homes or other long term care settings?

$\square$ Never

Less than once a week

Once a week or more

I've been practicing in a nursing home or long term care setting

\section{Thank you for taking the time to complete this questionnaire.}


$-29-$ 